\title{
Hand Hygiene Guidelines for Front Line Health Care Workers
}

\author{
Bhavanam Sai Rajendra \\ M.S.C (M.T) O.T and Anesthesia \\ Symbiosis Institute of Health sciences(SIU),Pune
}

\begin{abstract}
\section{Background:}

Hand hygiene competence is one of the critical outcomes for health care workers who are working for covid patients.. Ensuring health care workers to reduce the risk of infections among nurses and health care workers.
\end{abstract}

Adequate hand hygiene(HH) awareness for hospital staff like Nurses, ward technicians, health care workers should be implemented so as to reduce risks of facing infections.

\section{Objectives:}

To assess the knowledge and awareness programmes to the front line warriors who are in direct contact with covid patients.

\section{Design:}

A systematic review of studies published on January 1, 2009 based on, an online survey done in Canada where FIVE leading hospitals are actively involved and participated for Hand hygiene care.

\section{Methods:}

An online Data collection with simple and sample survey was conducted for Nurses, ward technicians, covid health care workers and Gram volunteers according to Guidelines given by World Health Organization's SEVEN ( 7) hand washing steps. The Data collection was taken from 50 Nurses and 50 covid health care workers particularly working in rural areas of Parchur Mandal of Prakasam District in Andhra Pradesh state.

Keywords:- Hospital-acquired infection, Behaviour, Quality improvement, Handwashing, Program evaluation, Review.

\section{INTRODUCTION}

Doroninaet al.,(2017) Reported effectiveness and 6month sustainability of the effect related, multimodaldirected and multimodal team leadership-directed strategies. To improve the hand hygiene techniques in super speciality hospitals

Olena et al., (2016) reported effectiveness and 6month sustainability of the effect related to multimodaldirected and multimodal with team leadership- directed strategies. The other two RCTs found positive effect of education and feedback on compliance; however, compliance rates declined after 1 month. Education was also found to improve HHC up to 3 months postintervention. An electronic reminder and feedback system evaluated by an ITS improved HHC and detected variation in $\mathrm{HHC}$ through the day.

Tabular Data

\begin{tabular}{|c|c|c|}
\hline Qualification & Number of persons & Percentage \\
\hline 1)Nurses & 50 & $60 \%$ \\
\hline 2)covid health care workers & 50 & $55 \%$ \\
\hline
\end{tabular}




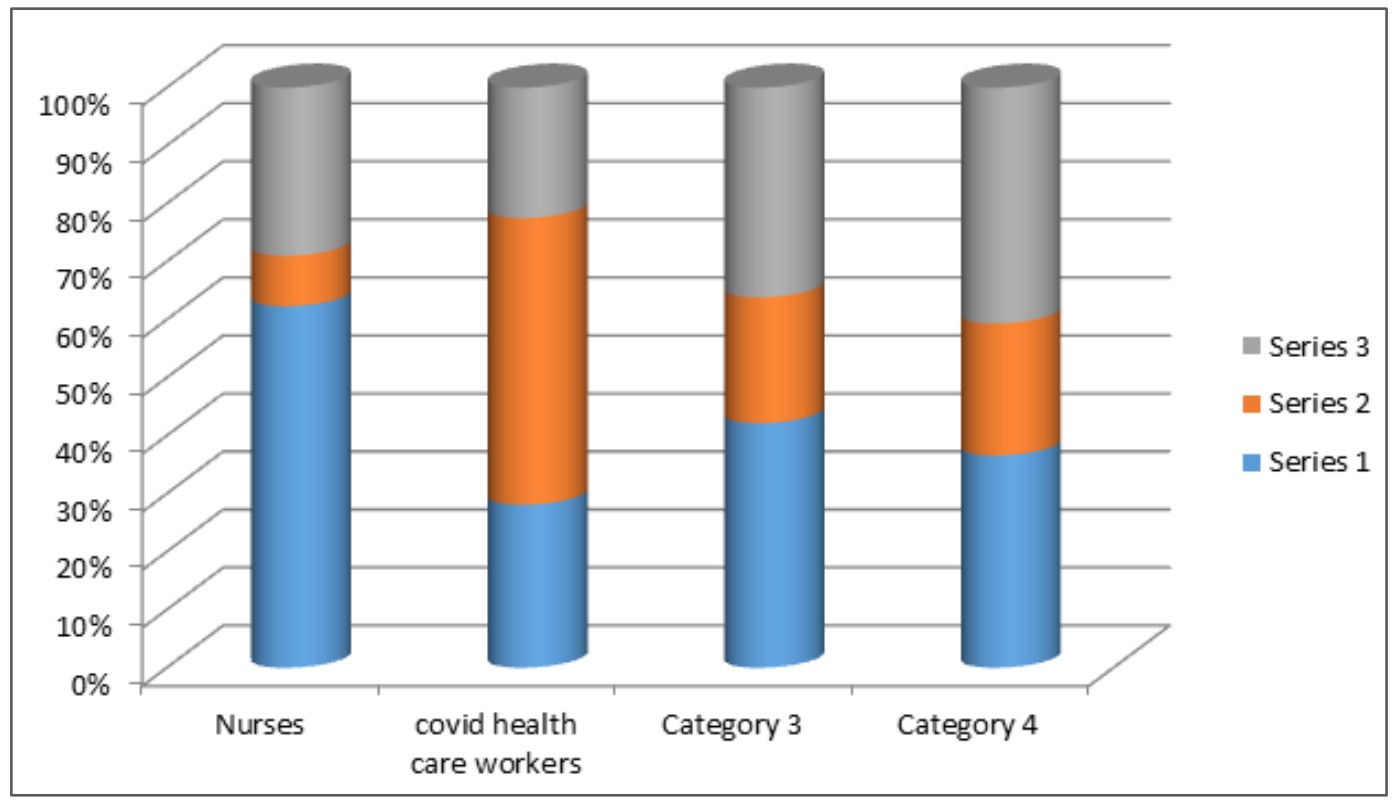

Fig 1

\section{RESULTS}

The Data collection has given the reports stating that $60 \%$ of nurses have adequate knowledge regarding hand hygiene in super speciality hospitals. The nurses and covid health care workers working in Rural Areas have poor knowledge in Hand washing steps and Guide lines given by WHO which may lead them towards infections.

\section{CONCLUSION}

Due to in sufficient knowledge in the rural area hospitals on hand hygiene, majority of the Nursing staff and other 4 th class employees are the sufferers with infections. As they need an orientation on hand hygiene, which would help them to avoid this kind of health issues. For this, the Doctors who are working in rural areas will have to be more cautious and careful with this kind of infections. And they need to provide frequent awareness programmes to all the staff and make them aware about proper hand hygiene care at regular intervals.

And also display of proper hand hygiene techniques will not only help the Nursing staff and health care workers but general public also get some knowledge and awareness through this.

\section{REFERENCES}

[1]. Sax H, et al. 'My five moments for hand hygiene': a user-centred design approach to understand, train, monitor and report hand hygiene. Journal of Hospital Infection

[2]. World Alliance for Patient Safety. The Global Patient Safety Challenge 2005-2006 "Clean Care is Safer Care". Geneva: World Health Organization; 2005.

[3]. Lopez AD, et al. Global and regional burden of disease and risk factors, 2001: systematic analysis of population health data. Lancet.
[4]. Pittet D, et al. Considerations for a WHO European strategy on healthcare-associated infection, surveillance, and control. Lancet Infectious Diseases. 2005;

[5]. Vincent JL. Nosocomial infections in adult intensive care units. Lancet.

[6]. Kim JM, et al. Multicenter surveillance study for nosocomial infections in major hospitals in Korea. Nosocomial Infect 